Diastase 中のフェールズルフォダーゼに竌て, 同

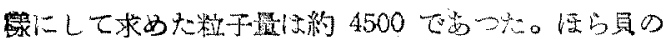

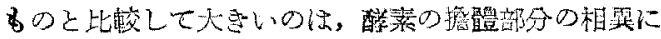

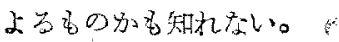

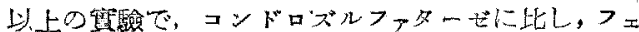
フールズルファターゼ,ダルコズルファターゼは料子是

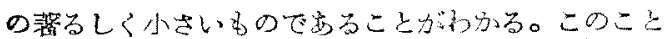
ば水酸化アルミニウムダルにより。コンドロズルファ

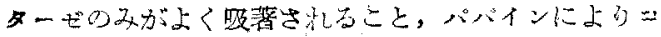

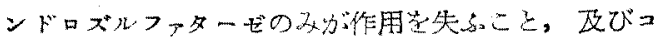

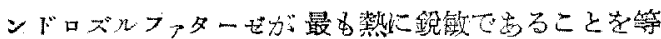

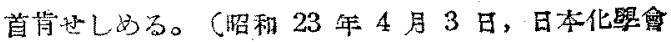

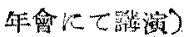

\section{一引用文晍 -}

1) J. Northrop, M. L.Anson, J. Gen. Physiot., $12,543(1929)$.

2) 左在田·笔良·依田，日化，62，1227(1941).

3) J.W.McBain, C.R.Dawson, H.A.Barker, J.A.C.S., 56, $1021(1934)$.

4) J. W. McBain, T. H. Liu, J. A. C. S., 53, $59(1931)$.

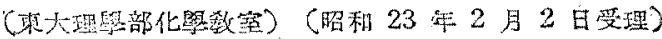

（65～66）强放射能泉中におけるラチウムの同位元素（第 2３ 報）

黑田和夫・灆山蹃之

に尉した道りでるる。

(第2 報)ラヂウムとトリウムXの沈澱

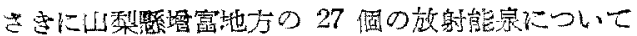

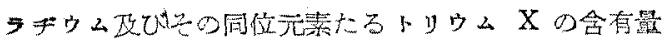

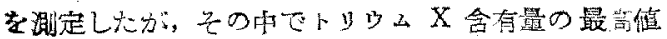
第 1 阔

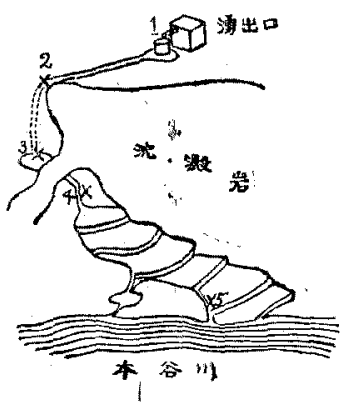

走示した B7 踪泉及

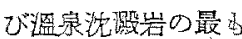

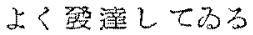

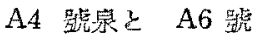
崇について, テギ ウム皮びトリウム X

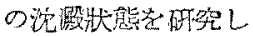

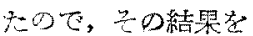
ニ〉に街告する。 ヂウム改びトりゥム

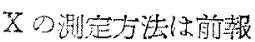

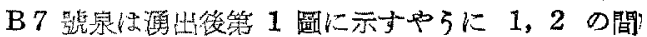

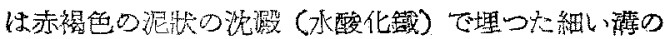

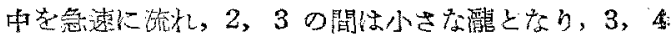

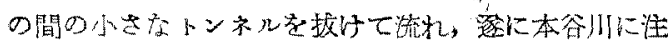

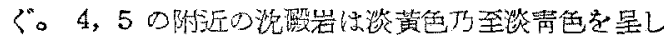

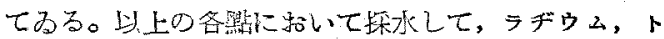

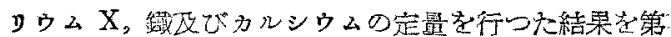

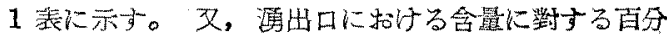

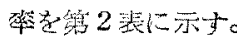

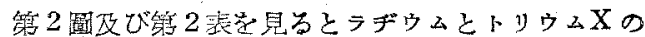

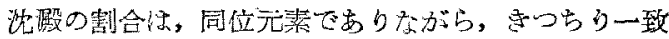
しない。この原图については色考入ら炕が，恐ら

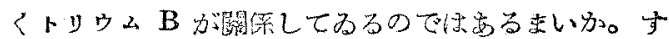
なはち第 1 裁、符 2 裴に示したトリウム X の値は

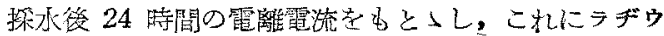

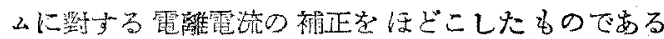

第 1 琵 B7 號泉(東小星の桌) 1947 年 8 月 13 日

\begin{tabular}{|c|c|c|c|c|c|c|c|}
\hline \multirow{2}{*}{ 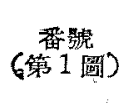 } & \multirow{2}{*}{ 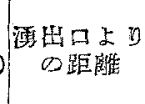 } & \multirow{2}{*}{$\left.{ }^{\circ}{ }^{\circ} C^{\circ}\right)$} & \multirow{2}{*}{ Ra 含嵔 } & \multicolumn{2}{|c|}{$\mathrm{ThX}$ 畣舅 } & \multirow{2}{*}{ Fe 合量 } & \multirow{2}{*}{$\mathrm{Ca}$ 全量 } \\
\hline & & & & (トyウム䟡位) & 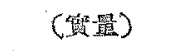 & & \\
\hline 1 & $0 \mathrm{~m}$ & 26.2 & $38 \times 10^{-12} \mathrm{~g} / \mathrm{l}$ & $24.4 \times 10^{-4}$ & $132 \times 10^{-17} \mathrm{~g} / l$ & $15.90 \mathrm{mg} / l$ & $0.367 \mathrm{~g} / /$ \\
\hline 2 & 7 & 26.5 & 30 & 22.6 & 122 & 7.72 & 0.356 \\
\hline 3 & 10 & 26.0 & 30 & 22.6 & 122 & 6.88 & 0.363 \\
\hline 4 & 12 & 25.7 & 24 & 17.7 & 90 & 4.86 & - \\
\hline 5 & 16 & 26.2 & $21^{\prime}$ & 14.5 & 78 & 3.98 & 0.320 \\
\hline
\end{tabular}


箱 2 表

\begin{tabular}{r|r|r|r|r}
\hline & $\mathrm{Ra}_{\mathrm{a}}$ & $\mathrm{Th} \mathrm{X}$ & \multicolumn{1}{|c|}{$\mathrm{Fe}$} & $\mathrm{Ca}$ \\
\hline 1 & 100 & 100 & 100 & 100 \\
2 & 79 & 92 & 49 & 97 \\
3 & 79 & 92 & 43 & 99 \\
4 & 63 & 73 & 31 & - \\
5 & 55 & 60 & 25 & 87 \\
\hline
\end{tabular}

管 2 阔

筷 3 圆
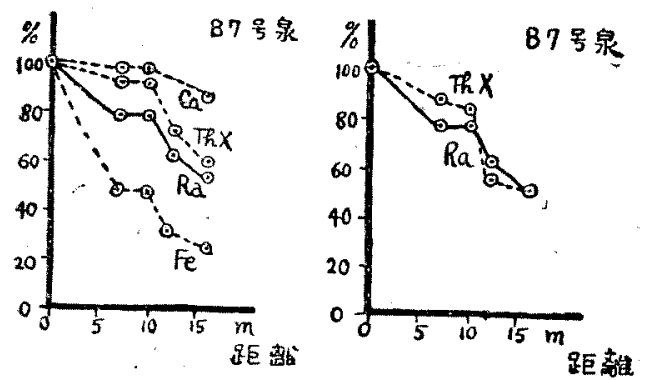

筑 3 表

\begin{tabular}{|c|c|c|}
\hline 舀量虎 & $T h X$ 会贯 & 沈洪百分到 \\
\hline 1 & $132 \times 10^{-1} \mathrm{ig} / l$ & $100: 0$ \\
\hline 2 & 118 & 88 \\
\hline 3 & 111 & 84 \\
\hline 4 & 77 & 58 \\
\hline 5 & 73 & 55 \\
\hline
\end{tabular}

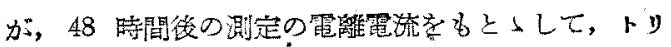

ウム X の量を計算すると籍 3 表のやらになる。距㷰

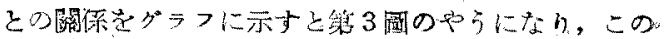

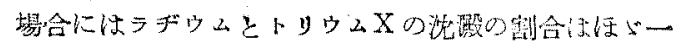
致してるる。結同坎のやらなことが言へるので㳖か

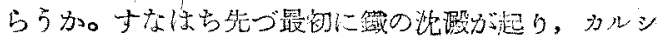

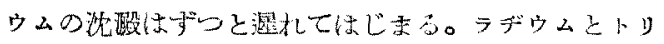

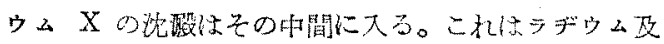

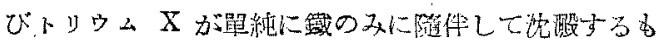

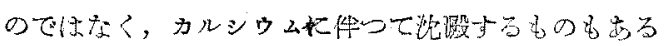

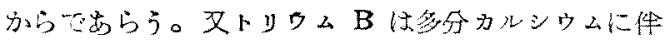

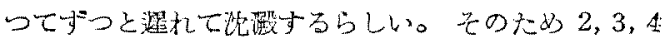

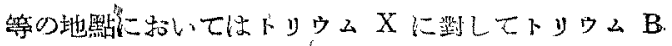
の渦剩が大ることつなりトリ日ムＢの牛減期が 10.6 時間で出るから，24 時間後の測定に岕いては。

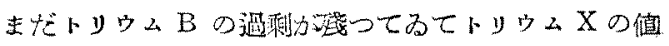

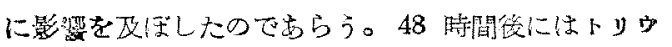
ム B とトリゥム $\mathrm{X} の$ 第 4 罩

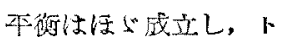
リウム B の影得は然 くなる。

A4 躆家不び A6 䟚

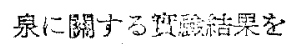
䈍 4 表法示与。第 4 阔 に示すやらにこの二つ の泉は遮䌑して居り， 5 の地盟に㟧いて囦 A6 跋宗の一部名方合 流なるために4の地黙 に轧けるよりラデゥム

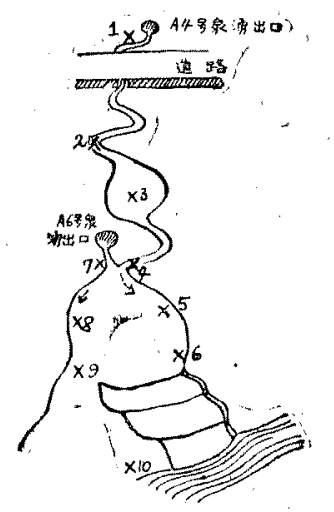

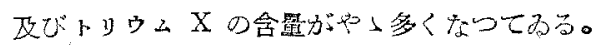

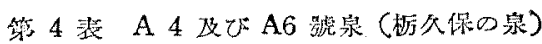
1947 年 8 月 15 日

\begin{tabular}{|c|c|c|c|c|c|c|c|}
\hline (番 4 淲 & \multicolumn{2}{|c|}{ 婳出口からの距離 } & 温度 & \multicolumn{2}{|c|}{$\mathrm{Ra}$ 含量 } & \multicolumn{2}{|c|}{$\mathrm{Th} \mathrm{X}$ 含量 } \\
\hline 1 & $0 \mathrm{~m}$ & & $28.0^{\circ} \mathrm{C}$ & $25 \times 10^{-19} \mathrm{~g} / l$ & $100 \%$ & $39 \times 10^{-1} \mathrm{~g} / l$ & $100 \%$ \\
\hline 2 & 7 & & 27.0 & 13 & 52 & 21 & 54 \\
\hline 3 & 12 & & 26.0 & 8 & 32 & 13 & 33 \\
\hline 4 & 18 & & 25.2 & 4 & 16 & 8 & 20 \\
\hline 5 & 21 & $2^{*} \mathrm{~m}$ & 25.3 & 8 & - & 9 & - \\
\hline 6 & 24 & $5^{*}$ & 25.5 & 5 & - & 3 & - \\
\hline 7 & & $1^{*}$ & 27 . & 26 & 100 & 23 & 100 \\
\hline 8 & & $3^{*}$ & 26 & 17 & 65 & 16 & 70 \\
\hline 9 & & $6^{*}$ & 25.1 & 8 & 31 & 8 & 35 \\
\hline 10 & & $11^{*}$ & 25 & 5 & 19 & 4 & 17 \\
\hline
\end{tabular}

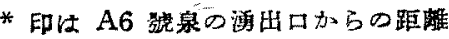




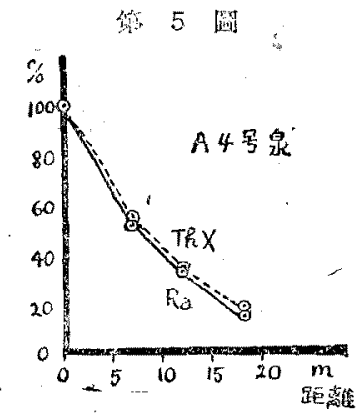

第 6 湿

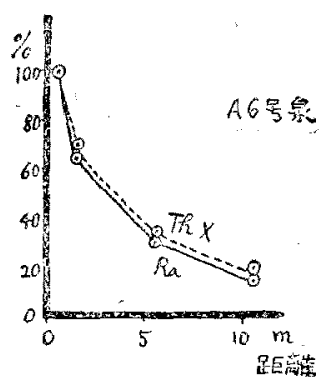

经 7 陮

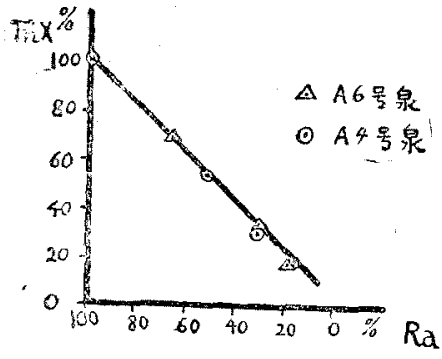

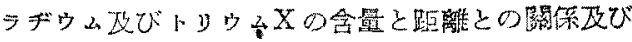

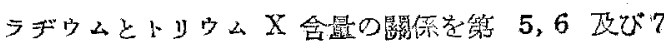
四に示古。この場合にはラヂウんとトリウムXは殆

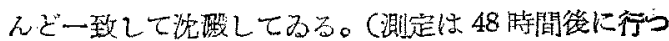

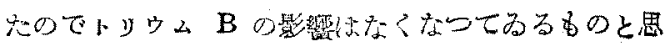

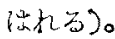

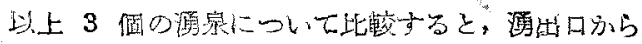

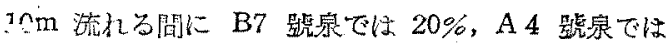

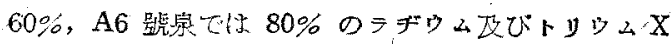

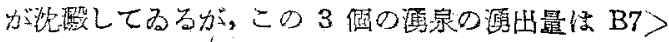
A4 $A 6$ の䐓更り, 從つて地表に出てからの流涑

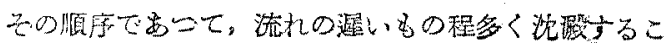
と軓示してるる。

\section{（第 3 報） ラヂウムとトリウムXの 存在量比と化學組成}

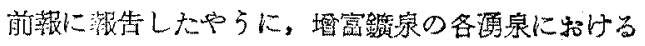

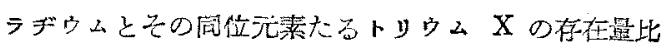

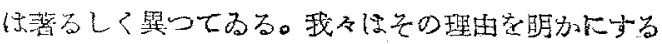

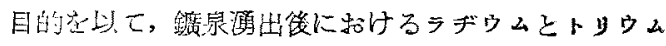

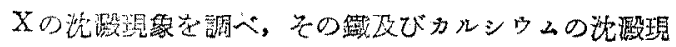

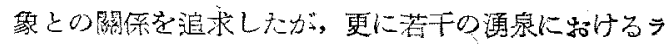

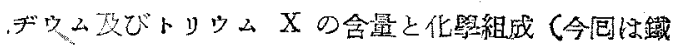

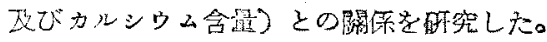

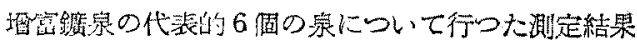

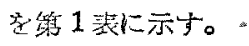

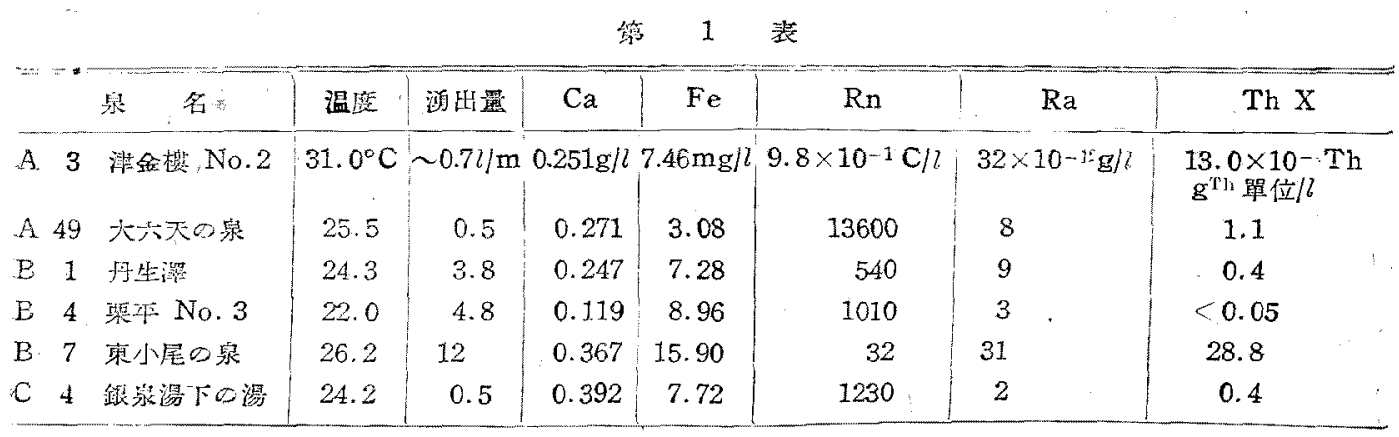

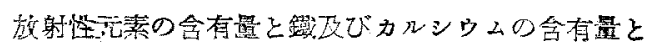

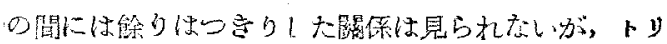

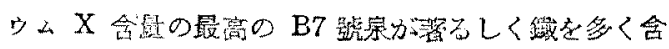

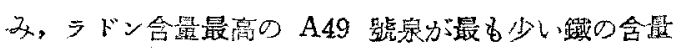
を示ナのは注局すべぎ恋る。

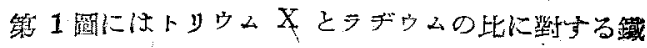

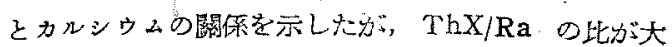

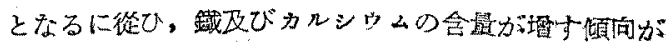
ある。(トリウム X とテデウムとの比は双方を

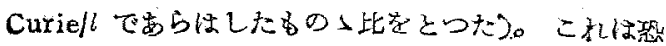

